\title{
Real STEM: An Interdisciplinary STEM Program
}

\author{
Robert Mayes $^{\mathrm{a} 1}$, Kent Rittschof ${ }^{\mathrm{a}}$, Bryon Gallant ${ }^{\mathrm{a}}$, Charlie Martin ${ }^{\mathrm{b}}$ \\ ${ }^{\mathrm{a}}$ Georgia Southern University, USA; ${ }^{\mathrm{b}}$ Georgia College and State University, USA
}

\begin{abstract}
The integration of STEM programs within the educational framework through the establishment of STEM-designated schools and academic/career pathways is a national trend in the United States. The goal of implementing STEM in grade 6 to 12 schools is to prepare students for the demands of the 21st century, while addressing future workforce needs. Often, however, the STEM disciplines are taught within silos independent of each other. Students miss the opportunity to participate in the interrelationship between the STEM disciplines, resulting in missed opportunities to build critical reasoning skills. The Real STEM project focused on the development of interdisciplinary STEM experiences for students. The project was characterized by sustained professional development which was job-embedded and competency-based, and focused on the development of five STEM reasoning abilities within real-world contexts. To accomplish this we promoted inclusion of tasks that drew on multiple STEM disciplines, embraced the use of authentic teaching strategies, and supported development of collaboration through interdisciplinary STEM professional learning communities within the school and STEM experts from the community. The four tenets of the Real STEM project are presented, research on impact on teacher practice is provided, and school and teacher takeaways are discussed.
\end{abstract}

Keywords: Interdisciplinary STEM, authentic teaching, collaboration, reasoning

\section{Real STEM: An Interdisciplinary STEM Program}

The integration of STEM into schools is a national trend in the United states, apparent in the call to establish STEM designated middle and high schools (President's Council of Advisors on Science and Technology, 2010; Tanenbaum, 2016), as well as in the creation of STEM academic/career pathways for future workforce development (National Research Council, 2013). The Next Generation Science Standards (2013) and the Common Core State Standards for Mathematical Practice (National Governors Association, 2010) provide science and engineering practices and mathematical practices that support the inclusion of STEM in schools. These practices include modeling, integrating mathematics and computational thinking into science, planning and carrying out investigations of real world problems, analyzing and interpreting data, and designing solutions. An important question that emerged from our project around implementation of these interdisciplinary practices was, how do educators trained in one of the STEM domains incorporate the less familiar practices into their schools and classrooms?

The Real STEM project addressed what we believe is one essential component in integrating STEM into middle schools (students ages 11 to 13) and high schools (students ages 14-18): sustained professional development in interdisciplinary STEM. Sustained professional development is job-embedded (Croft, Coggshall,

\footnotetext{
${ }^{1}$ Corresponding Author: Department of Teaching and Learning, Georgia Southern University, Statesboro, GA 30460. Contact: rmayes@georgiasouthern. edu

Mayes, R., Rittschof, K., Gallant, B., \& Martin, C. (2017). Real STEM: An Interdisciplinary STEM Program. Journal of Research in STEM Education, $3(1 / 2), 1-16$
} 
Dolan, and Powers, 2010; Huffman, Hipp, Pankake, and Moller, 2014) and competency-based (Burke, 2005), with the aims of building interdisciplinary professional learning communities (PLCs) consisting of school administrators and teachers of science, mathematics, technology, and engineering (Fulton and Britton, 2011). We conjectured that an interdisciplinary STEM program should provide support and mentoring for teachers in the following four key tenets supporting STEM teaching and learning:

- Interdisciplinary STEM: ensuring STEM is taught as an interdisciplinary approach (Stohlmann, Moore, and Roehrig, 2012)

- Authentic Teaching Strategies: incorporating project-based teaching, problem-based teaching, and place-based education strategies to actively engage students (Bell, 2010; Thomas, J. W., 2000; Boud and Feletti, 2013; Smith and Sobel, 2010)

- Collaboration: creating STEM PLCs within the school supported by community, business, research institute and school partnerships (Blankenship and Ruona, 2006; Council for Corporate and School Partnerships, 2001)

- STEM Reasoning: setting outcomes that go beyond student engagement to development of five 21st century STEM reasoning abilities (Holland, 2014; Schwarz, 2009; Wing, 2006; Householder and Hailey, 2012; Mayes, Forrester, Christus, Peterson, \& Walker, 2014)

Within this report, we first discuss the Real STEM project which was designed to actively engage schools in these tenets. Second, we present some results of the project impact on teacher practice. Third, we share some of what we saw as critical takeaways for successful implementation of interdisciplinary STEM programs in schools.

\section{Real Stem Project}

The Real STEM project was funded by the Georgia Department of Education Innovation Fund to provide professional development supporting implementation of interdisciplinary STEM experiences through course modules in existing courses, as well as through new interdisciplinary STEM courses at the middle school and high school grade levels. The project supported development of interdisciplinary STEM professional learning communities of teachers in 12 schools in Georgia, six paired high schools and feeder middle schools.

The primary student outcomes of the project were to 1) increase student engagement and persistence in STEM and 2) improve students' STEM reasoning. The intended long term outcomes of Real STEM were to meet future STEM workforce needs by increasing student retention in the STEM pipeline and to develop STEM literate citizens who can make informed decisions about grand challenges impacting their future. Teachers participated in summer workshops with professional development field experiences that prepared them to guide students in authentic interdisciplinary STEM research, modeling, and design experiences. As a part of these authentic experiences, teachers were mentored on collaborating with regional STEM experts and interdisciplinary STEM faculty to identify authentic place-based STEM challenges. The STEM research design experience was to be student centric, with students formulating research questions within the frame of challenges identified by STEM experts. The STEM experts were to mentor the teachers and support students as they explored their problem, collected data, and analyzed the data. These experts also served on panels to which students reported findings. Students were required to view the problem through interdisciplinary STEM lenses, bringing chemistry, biology, physics, earth sciences, computational science, engineering, and mathematics to bear on the problem where appropriate. The Real STEM leadership team led the summer workshop and conducted monthly classroom observations in the 12 partner schools over the five years of the project. The leadership team also studied the impact of the Real STEM program on 1) teacher practice, 2) student affect, and 3) student learning. The four tenets of the Real STEM program are described in the following sections. 


\section{Tenet 1: Interdisciplinary STEM Inclusion}

We take the perspective that a meaningful STEM task must incorporate at least two of the four STEM fields (Fig. 1). In our work with schools, we saw teacher's challenged to reach beyond their area of expertise to implement interdisciplinary tasks. We observed a lot of science and mathematics (S\&M) tasks "done to students" without meaningful interdisciplinary integration, as well as a lack of technology or engineering (T\&E) integration into tasks. We ask teachers to start by having students view problems through all four STEM lenses, before eliminating those that do not apply. We stress use of real-world problems, which are often interdisciplinary and occur in complex systems. This requires moving beyond teaching STEM in traditional content silos to taking an interdisciplinary STEM perspective. We also need to move beyond the traditional science paradigms of experimental science and theoretical science, to include the newer paradigms of computational science and data-intensive science (the T in STEM).

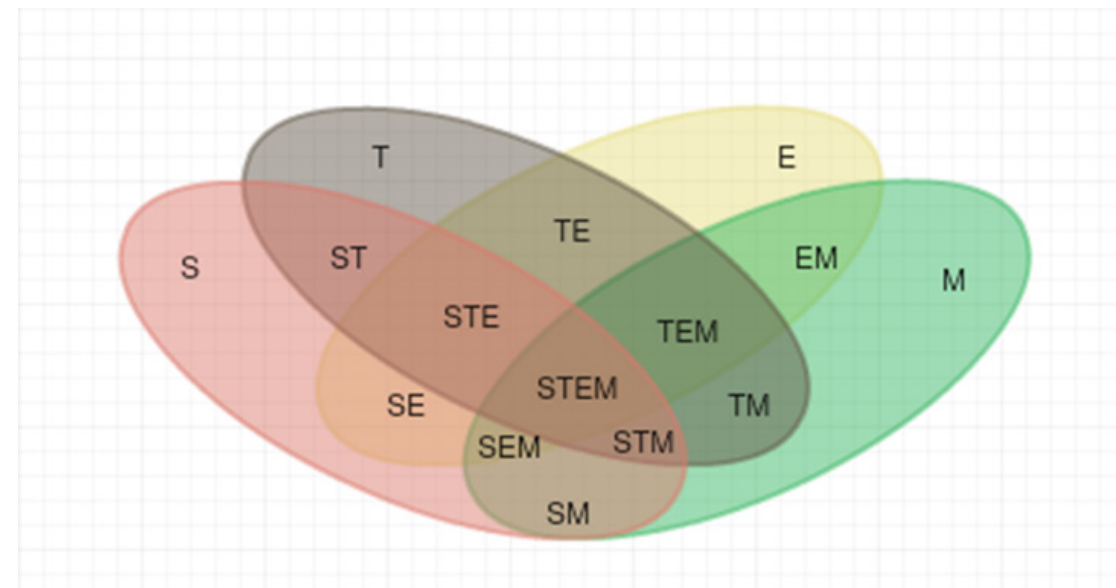

Figure 1. STEM is interdisciplinary, occurring at the intersection of at least two STEM fields

\section{Tenet 2: Authentic Teaching Strategies}

A primary project goal of integrating STEM into a school is to provide students with the opportunity to engage in real-world problem solving through hands-on experimentation, research, modeling, and design challenges. Broadening participation in STEM is best accomplished by moving towards more student-centric practices and moving away from the traditional teacher-directed classroom (Jones, 2007). We mentor teachers in implementing authentic teaching strategies including project-based learning (Buck Institute for Education, 2017), problem-based learning (Savery, 2006; Strobel and Barheveld, 2009), and place-based education (Smith and Sobel, 2010). A review of the literature provided a number of desirable authentic teaching characteristics (Edelson and Reiser, 2006) which are listed in Table 1. 
Table 1.

\section{Authentic Teaching and Learning Design Elements}

\begin{tabular}{ll}
\hline 1.Real-world relevance & $\begin{array}{l}\text { Learning rises to the level of authenticity when it asks students to work actively with abstract } \\
\text { concepts, facts, and formulae inside a realistic-and highly social-context mimicking the real world. }\end{array}$ \\
\hline 2. Ill-defined problem & $\begin{array}{l}\text { Challenges cannot be solved easily by the application of an existing algorithm; instead, activities are } \\
\text { relatively undefined and open to multiple interpretations, requiring students to identify the tasks and } \\
\text { subtasks needed to complete the major task. }\end{array}$ \\
\hline $\begin{array}{l}\text { 3. Sustained } \\
\text { investigation }\end{array}$ & $\begin{array}{l}\text { Authentic activities comprise complex tasks to be investigated by students over a sustained period of } \\
\text { time. }\end{array}$ \\
\hline $\begin{array}{l}\text { 4. Multiple sources and } \\
\text { perspectives }\end{array}$ & $\begin{array}{l}\text { Authentic activities provide the opportunity for students to examine the task from a variety of } \\
\text { theoretical and practical perspectives, using a variety of resources, which requires students to } \\
\text { distinguish relevant information in the process. }\end{array}$ \\
\hline $\begin{array}{l}\text { 5. Collaboration } \\
\text { 6. Reflection (metacog- } \\
\text { nition) }\end{array}$ & $\begin{array}{l}\text { Authentic activities make collaboration integral to the task, both within the course and in the real } \\
\text { world. }\end{array}$ \\
\hline $\begin{array}{l}\text { 7. Interdisciplinary } \\
\text { perspective }\end{array}$ & $\begin{array}{l}\text { Authentic activities have consequences that extend beyond a particular discipline, encouraging } \\
\text { students to adopt diverse roles and think in interdisciplinary terms. }\end{array}$ \\
\hline $\begin{array}{l}\text { 8. Integrated assessment } \\
\text { Assessment is not merely summative in authentic activities but is woven seamlessly into the major } \\
\text { task in a manner that reflects real-world evaluation processes. }\end{array}$ \\
$\begin{array}{ll}\text { 10. Multiple interpreta- } \\
\text { tions and outcomes }\end{array}$ & $\begin{array}{l}\text { Rather than yielding a single correct answer obtained by the application of rules and procedures, } \\
\text { authentic activities allow for diverse interpretations and competing solutions. }\end{array}$ \\
\hline
\end{tabular}

We found project-based learning to be a good initial step in implementing authentic teaching strategies. Project-based learning allows the teacher to remain in control of assigning the task, such as this Real STEM teacher engaging students in engineering water bottle rockets (Fig. 2). Project-based learning allows for inclusion of several but not all of the authentic learning characteristics including: 3) sustained investigation; 5) student collaboration through small group design teams; 6) reflection on learning; 7) interdisciplinary approaches; 8) integrated assessment through a performance task demonstrating understanding; and 9) polished final products.

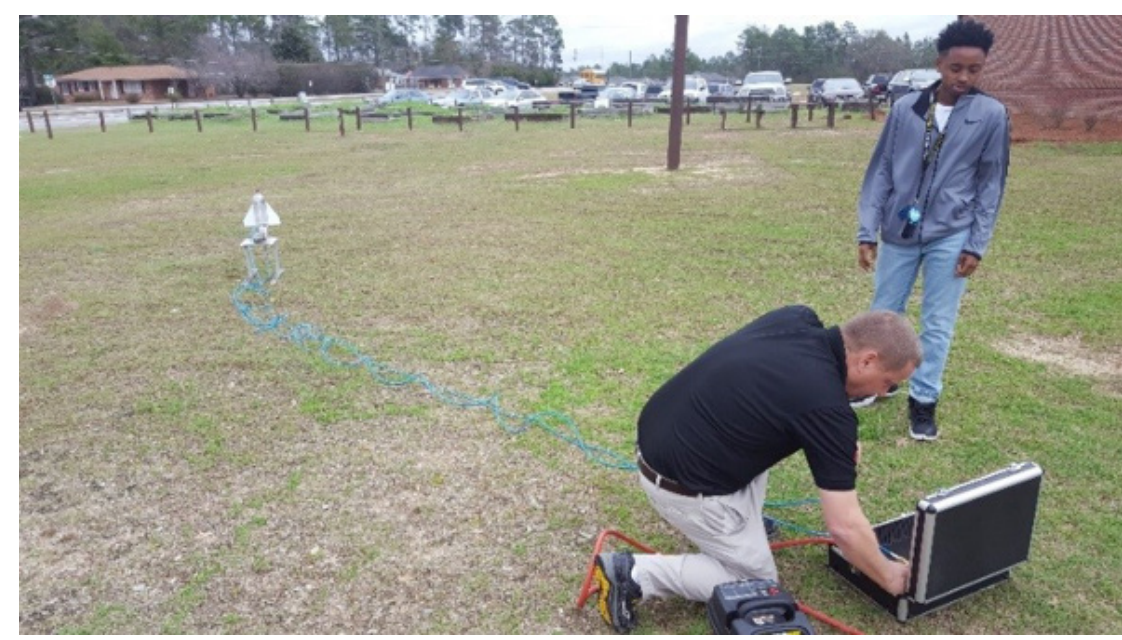

Figure 2. Project-based learning: Engineering water bottle rockets

Teacher-assigned projects allow the teacher to target specific STEM concepts, however this potentially restricts addressing other desirable authentic learning characteristics, including 1) real-world relevance for the student; 2) ill-defined, more open-ended problems; 4) requiring research into multiple sources and perspectives; and 10) diverse interpretations and outcomes. 
Problem-based learning can potentially incorporate all ten authentic learning characteristics, but this requires that teachers allow student input on selection of the problem. We found 1) real-world relevance for the student often was lacking if the teacher selected the problem. The more student-centric the problem selection was, the greater the potential engagement of the student. For example, a Real STEM teacher had students brainstorm potential STEM projects. The students chose the problem of building a full-scale electric car powered by a solar panel (Fig. 3).

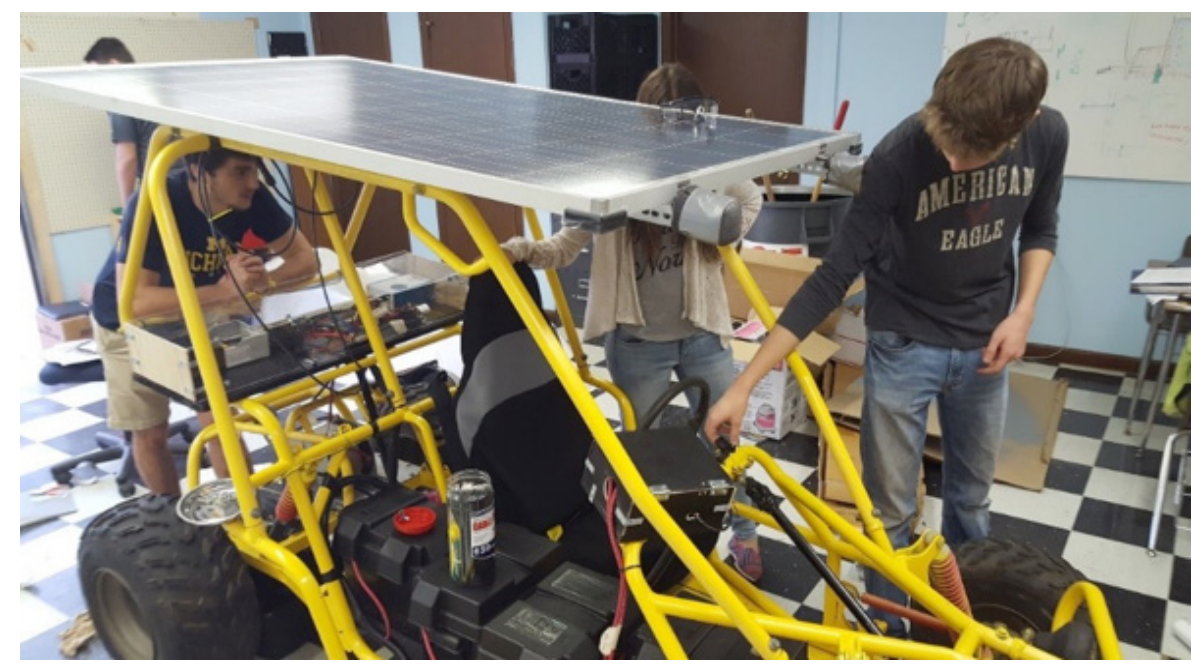

Figure 3. Problem-based learning: Designing an electric car

The students formed teams to work on different components of the car. The car is currently underway using battery power, though they were still working on incorporating the solar panel. Student selected problems can potentially come at the cost of targeting specific STEM concepts, since the problem drives what is studied. In response, learning outcomes need to shift from pre-determined content understanding to process abilities, such as reasoning and problem solving.

Place-based education incorporates authentic teaching elements 2 through 10, embraces a studentcentric focus, and motivates the final element: 1) real world relevance tied to student's locale. Students work within a realistic, social context related to their local place, providing the opportunity for a maximum studentcentric experience. We explore with teachers grand challenges within STEM fields identified by national/ international experts, such as the eight grand challenges of environmental science (National Research Council, 2001). Students connect the challenges to their locale and identify problems they would be interested in studying, following the environmental science call to "think globally, act locally". The problems are vetted through student peer mentors, the teacher professional learning communities, and community STEM experts. One of our Real STEM schools chose the grand challenge of hydrological forecasting. They revitalized a pond on the school property, studying parking lot drainage issues and the pond ecosystem (Fig. 4). The teacher professional learning communities in our partner schools have incorporated grand challenge problems into existing classes through STEM Fridays (dedicating a day to STEM) or by developing new STEM courses. 


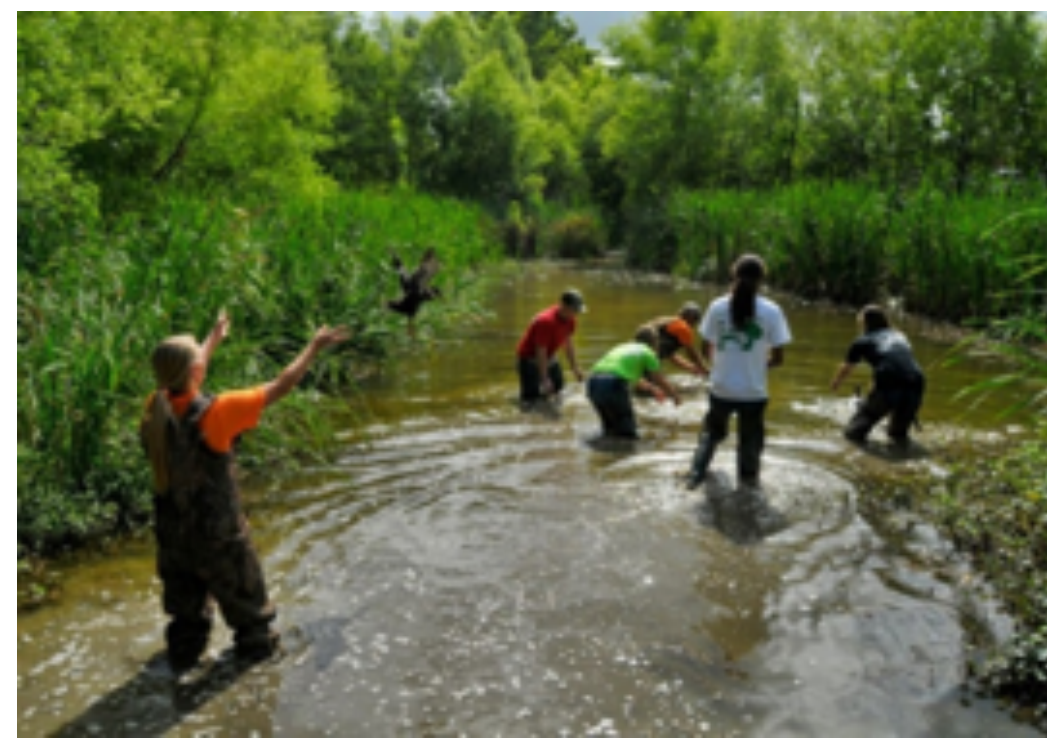

Figure 4. Place-based Education: Revitalizing a pond near the school

\section{Tenet 3: Community Collaboration}

Interdisciplinary STEM requires a team approach to teaching in order to support authentic real-world ill-structured problems (Blankenship and Ruona, 2006). Few teachers have the expertise to address different STEM aspects of such problems. First, teachers have to be comfortable with not knowing all the answers, and to be confident in saying, "I do not know, but let's work together to find out." Second, a strong teacher professional learning community is essential in providing expertise from multiple STEM areas. Real STEM schools established interdisciplinary STEM learning communities that included, at-minimum, teachers of science and mathematics, and when available engineering and technology teachers, as well as an administrator. The professional learning communities were to meet regularly to consult on implementing STEM tasks. Third, development of collaborations with STEM community experts is essential, including establishing STEM Advisory Boards consisting of business, industry, research institute, and government representatives (Council for Corporate and School Partnerships, 2001). We explore a continuum of STEM expert support levels with our participating partners: low intensity (guest expert, field trip), moderate intensity (mentor, STEM problem/ challenge, funding STEM materials/supplies), and high intensity (teacher externship, student internship, funding STEM professional development). Further, the Real STEM project hosted field trips for teachers to interact with STEM experts from areas as diverse as agriculture, energy, and ocean science (Fig. 5).
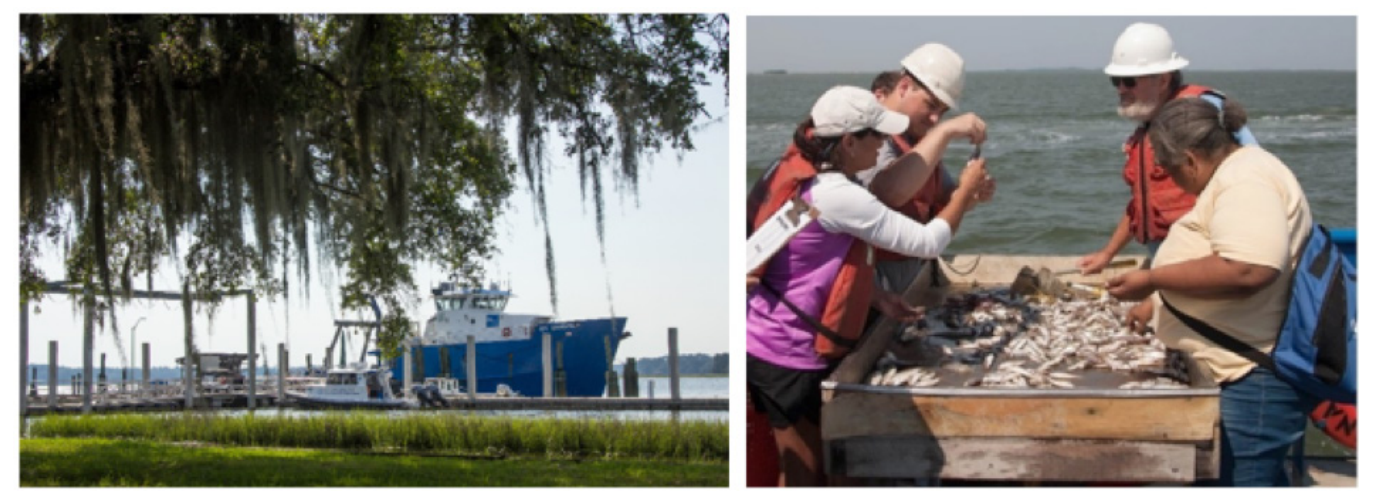

Figure 5. Teacher field trip on the UGA SKIO research vessel R/V Savannah, sailing out of Skidaway Institute for Oceanography: Teachers assist scientists with count from a trawling run. We thank the University of Georgia, Skidaway Institute of Oceanography for providing opportunities to REAL STEM members to participate in Oceanographic Research Expeditions aboard the Research Vessel Savannah. Ship time was 
supported by the US National Science Foundation in association with award OCE 1459293 to Marc E Frischer.

\section{Tenet 4: Reasoning Outcomes}

For interdisciplinary STEM programs to grow and be sustained they must do more than increase student engagement. STEM programs need to have established learning outcomes. What are the standards addressed by a STEM experience? What does STEM do for school science and mathematics test scores? We believe that the more student-centric and ill-structured a problem is, the more difficult it is to connect with predetermined STEM content standards. In fact, attempting to do so may inversely impact the open-ended nature of STEM tasks. To help address this dilemma we collaborate with teachers on linking their STEM tasks to process standards. The learning outcomes we highlight are the development of student ability to think like a scientist, think like a computer scientist, think like an engineer, and think like a mathematician. STEM experts have different problem solving processes, which while they overlap are not the same. Our review of the literature resulted in the identification of five STEM reasoning modalities which are 21st century abilities STEM experts call for students to develop: complex systems reasoning, scientific model-based reasoning, technological computational reasoning, engineering design-based reasoning, and mathematical quantitative reasoning. Figure 6 provides a short summary of the five reasoning abilities along with citations of some of the leading STEM experts promoting the reasoning abilities.

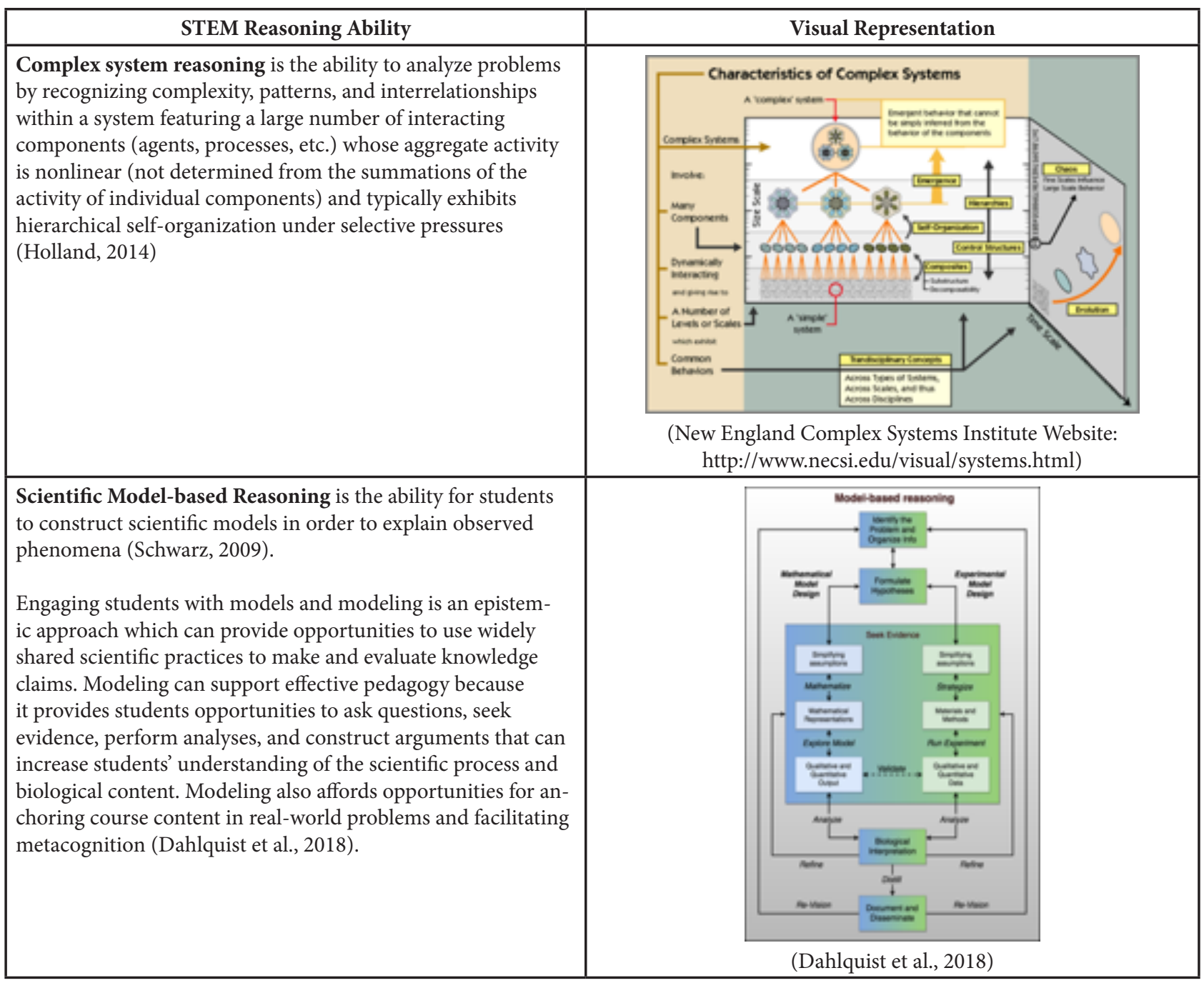


Technological Computational Reasoning is an analytical approach grounded in the computer sciences that includes a range of concepts, applications, tools, and skill sets that allow us to strategically solve problems, design systems, and understand human behavior by following a precise process that engages computers to assist in auto-mating a wide range of intellectual processes (Wing, 2006; Wilensky and Resnick, 1999)
Engineering Design-based Reasoning is the ability to engage in the engineering design process through implementation of a series of process steps to come up with a solution to a problem. Many times the solution involves designing a product (like a machine or computer code) that meets certain criteria and/or accomplishes a certain task (Householder and Hailey, 2012).
Mathematical Quantitative Reasoning is mathematics and statistics applied in real-life, authentic situations that impact an individual's life as a constructive, concerned, and reflective citizen. QR problems are context dependent, interdisciplinary, open-ended tasks that require critical thinking and the capacity to communicate a course of action (Mayes et al., 2014)

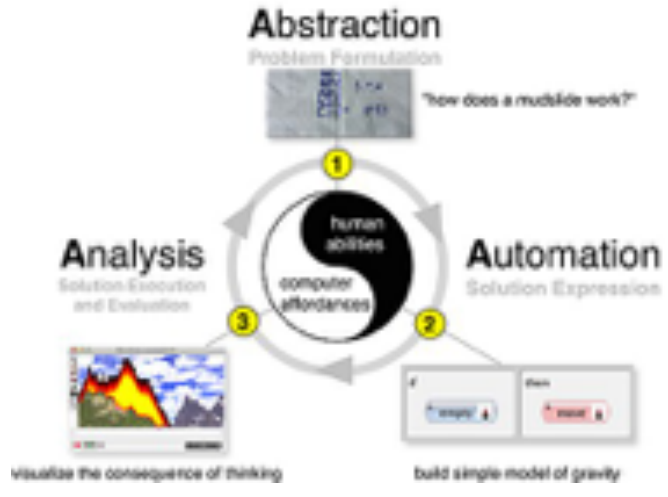

(Repenning, A. Basawapatna, and N. Escherle, 2016.)

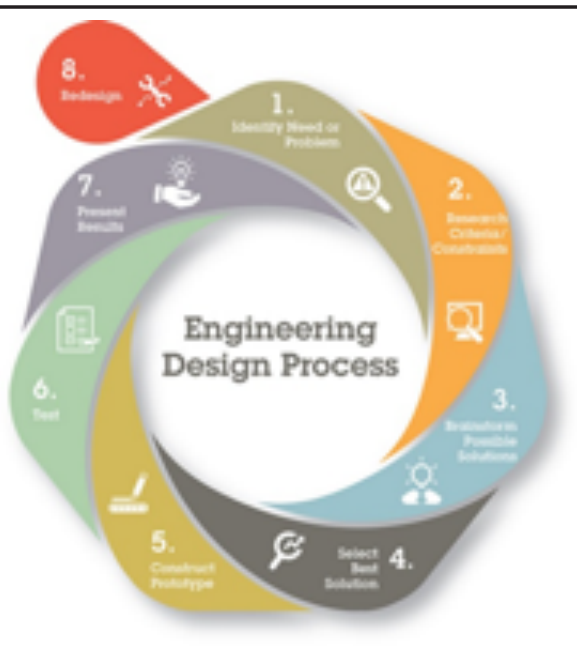

(Jenkins, 2015: Teaching Channel Website https://www.teachingchannel.org/blog/2015/09/29/rube-goldberg-machines-and-the-engineering-design-process/)

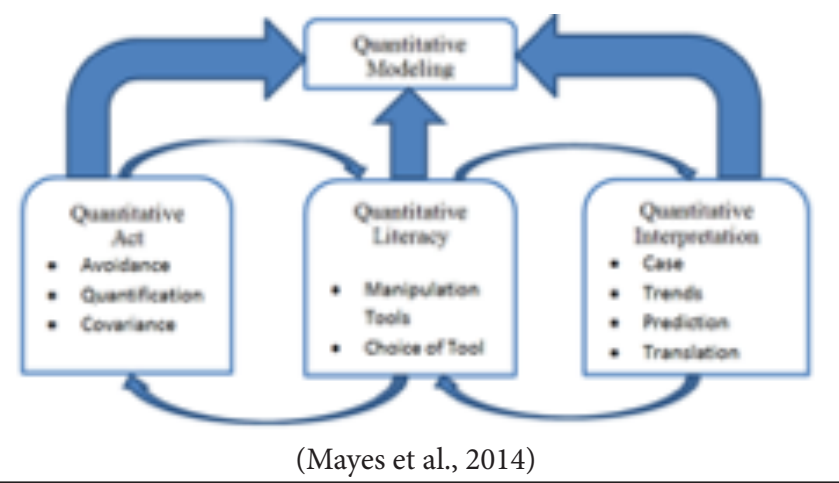

Figure 6. STEM reasoning modalities and visual representations

\section{Real Stem Evaluation}

The Real STEM project gathered data on impact of the project on teacher practice, student affect, and student reasoning. The tools used to analyze impact are described in this section.

Teacher practice was assessed through teacher interviews with focus groups, a Teacher Practice Survey, and Reform Teaching Observation Protocol (RTOP; Piburn and Sawada, 2000) class observations. The 
external evaluator conducted interviews with focus groups of teachers at the close of the summer professional development. The interviews focused on teachers understanding of project expectations, potential challenges, development of business/research institute partnerships, and what support would be helpful in the future. The focus groups consisted of PLC teachers from each of the participating schools. The Teacher Practice Survey was based on the Concerns-Based Adoption Model (CBAM; Loucks-Horsely, 1996), providing data on teachers concerns, confidence, and commitment in implementing interdisciplinary STEM experiences in schools. The CBAM was administered online through the Qualtrics survey tool and analyzed by the external evaluator for the Real STEM project. The RTOP was conducted monthly by the Real STEM team during observations of classrooms implementing interdisciplinary STEM experiences. RTOP (Piburn and Sawada, 2000) is an observational instrument for reformed teaching. The RTOP was modified to include categories for authentic teaching and interdisciplinary STEM.

Student affect was assessed through a Real STEM Student Survey administered online through the Qualtric survey tool and analyzed by the external evaluator for the project. The student survey link was provided to lead teachers of the STEM courses in participating schools. The teachers were requested to have all students participating in Real STEM courses complete the survey. The Student STEM Reasoning Assessment was developed by the Real STEM project team to assess student STEM reasoning across all five reasoning areas identified for the project. The assessment is multiple choice and administered online using the Qualtric survey tool. The lead teachers of the STEM courses were asked to administer the assessment as a pre-post, but due to the variety in implementation of the STEM courses across schools some teachers selected only to give the reasoning assessment as a post-test and others did not give the assessment.

Results of impact on students will be reported in a future paper under development by the research team. Here we focus on the Real STEM projects impact on teacher practice. The Real STEM program evaluation indicated several successful outcomes and documented areas needing improvement.

\section{Real STEM Focus Groups}

In the two focus groups reported on here, seven middle grades teachers, one high school teacher, and one high school administrator participated. Three teachers had participated in Real STEM for one year, one teacher for three years, and one teacher had three-months experience. Three other teachers and the administrator were new to Real STEM.

Understanding of Real STEM expectations. Teachers appeared to have a clear understanding of expectations for the research class they were developing. They mentioned that the courses were to engage students in real-world problem-based activities and that they were to incorporate a variety of reasoning skills. One teacher emphasized that the course was to enable students to think like people in STEM disciplines. Teachers also mentioned that they were expected to meet as a professional learning community to work on the course. All expressed concerns about their ability to do this effectively given lack of common planning time and challenges for scheduling meetings out of school time.

Partnering with businesses, scientists, and research institutions. Participants mentioned a variety of partners who were working with their classes. Responses included descriptions of partners more actively engaged working with students and not simply providing materials or field trips for the classes. Examples included: Lowes manager working with financial aspects of building projects; high tech industry partners (Flight Safety International, Gulf Stream Aviation using 3D CAD software); partner donating 24 laptops to the program; Fish and Wildlife; Georgia Department of Natural Resources; former air force fighter pilot that taught students how to fly space shuttle simulator at school; Mitsubishi Systems; Plant Vogel waste management; businesses sharing jobs of the future; solar farm electrical; local lumber company and auto company providing supplies.

Teaching Reasoning Skills. Responses were limited regarding the teaching of reasoning skills. Teachers talked about projects for which students had to use reasoning skills, but little on how they were teaching reasoning skills. One group talked about modeling reasoning skills in their course or unit. Another described 
how they get students to understand the fundamentals of what they are doing and get them to extrapolate how to work their way around problems.

Challenges to implementation. Focus group participants mention a number of challenges to implementation. Areas mentioned included getting students to think for themselves and to be self-motivated to find and use data, not enough time to address focus of project and to teach reasoning skills, having to come up with your own problems, scaling from the number of students they are currently serving to meet increasing demand for the class, difficulty accomplishing all the goals (research, reasoning skills, develop partners) in a one-semester course, and not having sufficient working computers to meet needs of students. Finally, several teachers said that they had difficulty getting together for PLC meetings because they did not have common planning time.

Administrative support. There was variety in the level of administrative support among the participants. Several teachers said their principals were very supportive or flexible. Others said their principals were also supportive so long as it did not cost anything, they did not need anything, or it would not get them in trouble. However others commented that they had very little support from their administrators and that they did not know about the project or how to support it.

Support from Real STEM. Participants were consistent in their praise for the support they received from Real STEM. One teacher described her relationship with project leaders as "mature" in which information passed in two ways. They explained that it was very easy to call if they had questions or needed help. Teachers said that project personnel checked in with their project at least once a month and that they were in the schools for events like STEM nights. Real STEM also provided teachers with ideas for resources as well as bringing books and other materials. Teachers expressed need for the project to provide more support in how to select place-based problems and assistance in building STEM Advisory Boards.

Summary comments. The teacher focus group demonstrates the interest and activity in developing STEM partnerships with businesses and research institutes as called for by the Real STEM project. While the teachers showed a good understanding of the goals of Real STEM, the areas of concern with reasoning outcomes, PLC organization, and varied levels of administrative support are reflected in the other assessments of the program as well. The middle schools have found it easier to have PLCs collaborating on STEM research and design courses, due to the cross disciplinary team structures that exist in many middle schools and the availability of connections courses as a natural place to implement STEM courses. Connections courses are 8th grade classes that provide for exploration of topics that promote interest in high school pathways such as connected STEM courses. The more subject area silo structure of high schools and the development and staffing of new courses in STEM make it more challenging for high schools to implement STEM courses. In order to overcome the PLC and structure issues of implementing interdisciplinary STEM programs, it was essential to have administrative support and participation. The Real STEM project called for interdisciplinary STEM PLCs that included an administrator to serve as champion for the program. In schools where the administration has taken on this role the STEM programs have done well. When administrative support has been laissez-faire the program has been dropped or relied on the efforts of a teacher champion and continued in only one course.

\section{Teacher Practice Survey}

All teachers assigned to Interdisciplinary STEM Professional Learning Communities (PLC) in partner schools were invited to complete the Real STEM Teacher Survey. The total number of teachers engaged in PLCs across all partner schools was $n=65$, of which 39 completed the survey ( $60 \%$ return rate). The return rate is indicative of the varying level of collaboration within the PLCs at different schools. PLCs varied in size from 2 to 17, with 8 of 12 PLCs of size 3 to 4 . Some PLCs were very active, with the PLC team meeting regularly to plan tasks for the STEM courses, while other STEM courses were planned primarily by the lead teacher. Of those completing surveys, 7 (17.9\%) were in their first semester as Real STEM participants, 22 (56.4\%) were in their second semester, and $11(28.2 \%)$ had participated in more than three semesters. When asked what best 
described their role in Real STEM, 11 (28.2\%) responded that they taught a Real STEM course, 8 (20.5\%) taught a module or unit, and $21(53.8 \%)$ were members of learning communities.

The Teacher Survey is based on a Concerns-Based Adoption Model, a well-established model for studying how people develop as they learn about and adopt an innovation. The survey asks teachers to rate their level of concern, confidence and commitment with implementing the Real STEM tenets of 1) collaboration with experts; 2) authentic instruction; 3) teaching for understanding; 4) interdisciplinary STEM; and 5) STEM reasoning. The teachers rate their levels on a scale from 1 to 5 by reflecting back on how they felt at the beginning of participation in Real STEM and how they felt at the end of the school semester. Data from Fall 2016 on this survey indicated a statistically significant decrease in concern, increase in confidence, and increase in commitment to implementation on all five Real STEM tenets. We provide a more detailed analysis of the Spring 2017 implementation.

The results from the Spring 2017 implementation of the Teacher Survey are summarized in Table 2. The results from Fall 2016 were replicated, with statistically significant improvement (with probability level set to $\mathrm{p}<.001$ to account for the multiple comparisons) on all three levels on all five tenets. The teachers were less concerned, more confident and had increased commitment to implement the tenets of the Real STEM Project. The average change across all levels was 1.2, moving from an average of 2.5 to 3.7 on a 5 point scale, or an approximately $48 \%$ average change from the initial rating toward more STEM supportive views among teachers. The highest final mean values are in the area of commitment to implement the tenets. While there was growth in all areas, there is room for improvement in all areas with no highest mean rating exceeding 4 out of a possible 5 .

Table 2.

Teacher Survey Paired Sample T-test

Differences from beginning of participation to end of implementation

\begin{tabular}{lllcccc}
\hline Levels & Tenets & Mean & Mean End & Std. Dev. & T-value & $\begin{array}{c}\text { p-value } \\
\text { Significance }\end{array}$ \\
\hline \multirow{5}{*}{ Concern } & Collaboration Experts & 2.08 & 3.54 & 1.144 & -7.982 & 0.001 \\
& Authentic Instruction & 2.26 & 3.67 & 1.141 & -7.721 & 0.001 \\
& Teaching Understanding & 2.79 & 3.85 & 1.169 & -5.618 & 0.001 \\
& Interdisciplinary STEM & 2.18 & 3.54 & 1.328 & -6.393 & 0.001 \\
& STEM Reasoning & 2.21 & 3.38 & 0.997 & -7.391 & 0.001 \\
\hline \multirow{5}{*}{ Confidence } & Collaboration Experts & 2.16 & 3.42 & 1.267 & -6.147 & 0.001 \\
& Authentic Instruction & 2.45 & 3.55 & 1.290 & -5.281 & 0.001 \\
& Teaching Understanding & 2.84 & 3.89 & 1.229 & -5.279 & 0.001 \\
& Interdisciplinary STEM & 2.47 & 3.79 & 1.297 & -6.255 & 0.001 \\
& STEM Reasoning & 2.45 & 3.55 & 1.181 & -5.771 & 0.001 \\
\hline \multirow{5}{*}{ Commitment } & Collaboration Experts & 2.76 & 3.89 & 1.095 & -6.372 & 0.001 \\
& Authentic Instruction & 2.74 & 3.92 & 1.036 & -7.046 & 0.001 \\
& Teaching Understanding & 3.18 & 4.00 & 1.010 & -4.981 & 0.001 \\
& Interdisciplinary STEM & 2.79 & 3.95 & 1.175 & -6.076 & 0.001 \\
& STEM Reasoning & 2.92 & 3.97 & 1.089 & -5.957 & 0.001 \\
\hline
\end{tabular}




\section{RTOP Observation}

The modified RTOP observation instrument consists of qualitative and quantitative observations of project implementation in the classroom. The qualitative observations include the learning environment (e.g., student makeup, classroom setting), a program report section of overall project implementation, and summary lesson observation write-up. These qualitative observations were used to frame the state of school implementation.

The quantifiable observations include instructional strategies (authentic instruction, teaching for understanding, interdisciplinary STEM, STEM reasoning, and delivery), which are observed on 10 minute intervals and logged on an observation rating chart. Table 3 provides summary data on the quantitative observations across all participating schools (data represents estimated fractions of time a category was observed, e.g. 0.96 out of 1 or $96 \%$ of the time).

Table 3.

\section{RTOP Observation Averages}

\begin{tabular}{llc}
\hline Categories & Elements of Category & $\begin{array}{c}\text { Observation } \\
\text { Averages }\end{array}$ \\
\hline & Authentic Instruction: real world relevance, PBL/PBE, collaboration, student centric & 0.96 \\
& Teaching Understanding: enduring understanding, essential question, authentic assessment, & 0.77 \\
Instructional & performance task & 0.68 \\
Strategies & Interdisciplinary STEM: multidiscipline, STEM connections & 0.14 \\
& Delivery: lecture, discussion, assessment, administrative task & 0.86 \\
& Delivery: hands-on, active learning & 0.05 \\
& STEM Reasoning CS: complex systems & 0.21 \\
Reasoning & STEM Reasoning MB: science model-based & 0.13 \\
& STEM Reasoning CR: technology computational & 0.38 \\
& STEM Reasoning DR: engineering design-based & 0.26 \\
\hline
\end{tabular}

The instructional strategies category provides averaged estimates of the percentages of class time spent on each area based on two observations by the project leader, providing a snapshot from two class periods of what is happening in practice. In two class observations we do not expect to see all the elements in a category. So what does this snapshot tell us? Authentic teaching practices were displayed approximately $96 \%$ of the time for the two observations per 12 classes observed. Teaching for understanding practices were evident approximately $77 \%$ of the time in classes observed. Interdisciplinary STEM was evident approximately $68 \%$ of the time, with teachers engaging students in more than one STEM area. Discussion or hands-on activities occurred approximately $86 \%$ of the time, with passive delivery of material occurring only approximately $14 \%$ of the time. This is evidence that the teachers were implementing the active teaching tenet of the program.

There was a great deal of variation in which reasoning modalities were the focus of the class sessions, which is not surprising. We do not expect that all five reasoning modalities would appear every day. The majority of the Real STEM courses used either science or engineering as a driver for the course, so it is not unexpected that two of the three most occurring reasoning modalities were engineering design-based reasoning (approximately 38\%) and science model-based reasoning (approximately 21\%). Mathematical quantitative reasoning was also one of the most observed modalities (approximately 26\%) due to the integration of mathematics into the engineering and science tasks, primarily through either measurement or statistics. Technological computational reasoning (approximately 13\%) was the least evident among the four basic STEM reasoning modalities. We believe this is due to a lack of teacher preparation in computational science, since most teachers do not have a background in computer science. The majority of the teachers viewed the $\mathrm{T}$ in STEM as using technology as a tool (i.e. using a computer or calculator), rather than as teaching students to 
think like a computer scientist. Some teachers had begun incorporating computational reasoning through the use of Arduino (small microcontroller board) based tasks, but targeted professional development in the area of technology appears to be needed. Finally, while STEM tasks were often embedded in complex real-world systems, overall teachers were not explicit about engaging students in understanding the system. Indeed, while the percentages indicate the estimated amount of time spent on STEM reasoning modalities in the observed sessions, the number says nothing about the quality or depth of engagement in the reasoning modality. Overall the exposure to the reasoning modalities individually is positive, but increasing exposure to multiple reasoning modalities in the same class to increase interdisciplinary STEM focus should be a goal of interdisciplinary STEM courses. The variability in the STEM programs at the 12 schools, which we consider a strength, make the validity of this overall average something that needs to be considered when interpreting the value. We provide the average as a quick means of seeing the overall implementation in the observed classes.

\section{Summary}

The Real STEM project allowed for each school partner to implement a STEM program that addressed the unique needs of their students and the configuration of their school. The resulting variation in program implementation across schools should be taken into consideration when interpreting the results.

\section{Teacher Practice}

The teachers participating in the Real STEM professional development expressed significantly reduced concerns (1.3 gain or a 56\% higher average rating), higher confidence in (1.2 gain or $47 \%$ higher average rating), and stronger commitment to implementing (1.1 gain or 37\% higher average rating) the five tenets of teaching STEM proposed by the project. RTOP classroom observations of the interdisciplinary STEM courses in the 12 participating schools observed a strong implementation of authentic teaching strategies, teaching for understanding, providing interdisciplinary STEM opportunities to students, and focusing on active hands-on learning. The reasoning modalities most often observed were engineering design-based reasoning, mathematics quantitative reasoning, and science model-based reasoning.

We recommend:

1. sustained professional development for all teachers on integrating STEM through interdisciplinary STEM Professional Learning Communities (PLC) (Blankenship and Ruona, 2006; Fulton and Britton, 2011; Huffman, Hipp, Pankake, and Moller, 2001; Croft, Coggshall, Dolan, and Powers, 2010; Loucks-Horsely, 1996)

2. professional development focused in the areas of complex systems reasoning (Bar-Yam, 2005; Holland, 2014) and technology computational reasoning (Bitesize BBC, 2018), if these are desired areas of focus

3. administrative support in developing school-community partnerships that promote collaboration with STEM experts (Burke, 2005; Jones, 2007; Piburn and Sawada, 2000; Smith and Sobel, 2010)

School and Teacher Takeaways

Schools and teachers implementing STEM programs can take the following away from our Real STEM project experience.

- Interdisciplinary STEM professional learning communities are critical to the success of your STEM program. Interdisciplinary STEM teaching requires experts from multiple areas (Tanenbaum, 2016; Fulton and Britton, 2011)

- Administrative level support for STEM is essential if the program is to grow beyond dedicated first-adaptors. Develop a school wide STEM plan and provide time for professional learning 
communities to jointly plan curriculum (Huffman, Hipp, Pankake, and Moller, 2001).

- Develop community STEM partnerships that encourage place-based real-world problem solving and provide regional experts to partner with teachers (Smith and Sobel, 2010). Rural communities are more isolated resulting in less opportunities to interact with STEM researchers, but STEM experts exist in most communities, such as the county agricultural extension agent, and technology can provide online interactions with more distant experts (Council for Corporate and School Partnerships, 2001).

- Authentic teaching strategies are paramount to engaging students in authentic STEM problems (Bell, 2010; Boud and Feletti, 2013; Savery, 2006). Interdisciplinary STEM requires a change in teacher practice.

- Set appropriate learning goals for your STEM program which focus on process abilities such as reasoning and problem solving (Mayes, 2014). Move beyond engaging activities to authentic tasks.

\section{Acknowledgement}

This material is based on work supported by the U.S. Department of Education and Georgia GOSA. Any opinions, findings, conclusions or recommendations expressed in this material are those of the authors and do not necessarily reflect the views of the funding agencies.

\section{References}

Bar-Yam, Y. (2005). Making Things Work: Solving complex problems in a complex world. Cambridge, MA: New England Complex Systems Institute Knowledge Press.

Bell, S. (2010). Project-Based Learning for the 21st Century: Skills for the Future. The Clearing House: A Journal of Educational Strategies, Issues and Ideas, 83(2), 39-43.

Bitesize BBC. (2018). What is computational thinking? https://bbc.com/education/guides/zp92mp3/revision/1.

Blankenship, S. S. \& Ruona, W. E. A. (2006). Professional learning communities and communities of practice: A comparison of models, literature review. Journal of Educational Change, 7, 221-258.

Boud, D. \& Feletti, G. (2013). The Challenge of Problem-based Learning (2nd edition). London: Kogan Page.

Buck Institute for Education (2017). What is project-based learning? Retrieved from https://www.bie.org/ about/what_pbl.

Burke, J. (2005). Competency based education and training. London: Taylor \& Francis Group.

Council for Corporate and School Partnerships (2001). Guiding principles for business and school partnerships.

Croft, A., Coggshall, J. G., Dolan, M., \& Powers, E. (2010). Job-embedded professional development: What it is, who is responsible, and how to get it done well. National Comprehensive Center for Teacher Quality. Retrieved from https://files.eric.ed.gov/fulltext/ED520830.pdf.

Dahlquist K.D., Aikens M.L., Dauer J.T., Donovan S.S., Eaton C.D., Highlander H.C., Jenkins K.P., Jungck J.R., LaMar M.D., Ledder G., Mayes R.L., \& Schugart R.C. (2017). An invitation to modeling: building a community with shared explicit practices. PeerJ Preprints 5:e3215v1 https://doi.org/10.7287/peerj.preprints.3215v1

Edelson, D. C., \& Reiser, B. J. (2006). Making authentic practices accessible to learners: Design challenges and strategies. In R. K. Sawyer (Ed.), The Cambridge Handbook of the Learning Sciences, (pp. 335-354). Cambridge, UK: Cambridge University Press. 
Fulton, K. \& Britton, T. (2011). STEM Teachers in Professional Learning Communities: From good teachers to great teaching. National Commission on Teaching and America's Future: Washington, D.C. Retrieved from https://nctaf.org/wp-content/uploads/ 2012/01/ NCTAFreportSTEMTeachersinPLCsFromGoodTeacherstoGreatTeaching.pdf

Holland, John H. (2014). Complexity: A Very Short Introduction. New York: Oxford Press.

Householder, D. L., \& Hailey, C. E. (2012). Incorporating engineering design challenges into STEM courses. National Center for Engineering and Technology Education. Retrieved from http://ncete.org/flash/pdfs/ NCETECaucusReport.pdf.

Huffman, J. B., Hipp, K. A., Pankake, A. M., \& Moller, G. (2001). Professional learning communities: Leadership, purposeful decision making, and job-embedded staff development. Journal of School Leadership, 11(5), 448-463.

Jenkins, T. (2015). Rube Goldberg Machines and the Engineering Design Process. Teaching channel. https:// www.teachingchannel.org/blog/2015/09/29/rube-goldberg-machines-and-the-engineering-designprocess/

Jones, L. (2007). The Student-Centered Classroom. New York: Cambridge University Press.

Justi, R. S. \& Gilbert, J. K. (2002). Modelling, teachers' views on the nature of modelling, and implications for the education of modellers. International Journal of Science Education, 24(4), 369-387.

Loucks-Horsely, S. (1996). Professional development for science education: A critical and immediate challenge. In National Standards and the Science Curriculum, Bybee, R. (Ed), Dubuque, IA: Kendall/Hunt Publishing Co.

Mayes, R., Forrester, J., Christus, J. S., Peterson, F., \& Walker, R. (2014). Quantitative reasoning learning progression: matrix. Numeracy, 7(2).

National Governors Association Center for Best Practices, Council of Chief State School Officers

(2010). Common core state standards for mathematics. Washington D.C.: NGAC, CCSSO.

National Research Council (2001). Knowing what students know: The science and design of education assessment. Committee on the Foundations of Assessment. J. W. Pellegrino, N. Chudowsky, \& R. Glaser (Eds.) Board on Testing and Assessment, Center for Education, Division of Behavioral and Social Sciences and Education. Washington, D.C.: National Academies Press.

National Research Council. (2013). Monitoring progress toward successful K-12 STEM education: A nation advancing?. Committee on the Evaluation Framework for Successful K-12 STEM Education, Board on Science Education and Board on Testing and Assessment, Division of Behavioral and Social Sciences and Education. Washington, D.C.: The National Academies Press.

Next Generation Science Standards. (2013). Next generation science standards: For states, by states. Washington, D.C.: The National Academies Press.

Piburn, M., \& Sawada, D. (2000). Reformed teaching observation protocol (RTOP) Reference Manual, National Science Foundation: Arlington, VA.

President's Council of Advisors on Science and Technology (2010). Prepare and inspire: K-12 education in science, technology, engineering, and math (STEM) for America’s future. Retrieved from https://nsf.gov/ attachments/117803/public/2a--Prepare_and_Inspire--PCAST.pdf.

Repenning, A., Basawapatna, A., \& Escherle, N. (2016). Computational Thinking Tools. IEEE Symposium on Visual Languages and Human-Centric Computing, Cambridge, UK, 2016.

Savery, J. R. (2006). Overview of problem-based learning: Definitions and distinctions. Interdisciplinary Journal of Problem-based Learning, 1(1), 9-20. 
Schwarz, C. (2009). A learning progression of elementary teachers' knowledge and practices for modelbased scientific inquiry. Paper presented at the annual meeting of the American Educational Research Association, San Diego, CA, 2009.

Smith, G. A., \& Sobel, D. (2010). Place and community based education in schools. New York, NY: Routledge.

Stohlmann, M., Moore, T. J. \& Roehrig, G. H. (2012). Considerations for Teaching Integrated STEM Education. Journal of Pre-College Engineering Education Research, 2(1), https://doi.org/10.5703/1288284314653.

Strobel, J., \& Barneveld, A. (2009). When is PBL more effective? A meta-synthesis of meta-analyses comparing PBL to conventional classrooms. Interdisciplinary Journal of Problem-based Learning, 3(1), 44-58.

Tanenbaum, C. (2016). STEM 2026: A vision for innovation in STEM education. American Institutes for Research. Retrieved from http://www.air.org/system/files/downloads/report/STEM-2026-Vision-forInnovation-September-2016.pdf.

Thomas, J. W. (2000). A review of research on project-based learning. San Rafael, CA: Autodesk Foundation.

Wilensky, U. \& Resnick, M. (1999). Thinking in levels: A dynamic systems perspective to making sense of the world. Journal of Science Education and Technology, 8(1), 3-19.

Wing, J. M. (2006). Computational thinking. Communications of the ACM, 49(3), 33-35. 